\title{
sciendo
}

Folia Oeconomica Stetinensia

Volume 20 (2020) Issue 2

DOI: $10.2478 /$ foli-2020-0054
WYDZIAL NAUK EKONOMICZNYCH I ZARZAQDZANIA

\section{IDENTIFICATION OF OUTLIERS IN HIGH DENSITY AREAS \\ WITH THE USE OF A QUANTILE REGRESSION MODEL}

Tomasz Szkutnik, Ph.D.

University of Economics in Katowice

Faculty of Management

Department of Mathematics, Statistics and Econometrics

Bogucicka 3, 40-287 Katowice, Poland

e-mail: tomasz.szkutnik@uekat.pl

ORCID: 0000-0002-2565-6802

Received 3 November 2019, Accepted 12 October 2020

\begin{abstract}
Research background: The study exemplifies the issues presented in the international trade data, which can affect the efficiency of customs controls in clearance systems.

Purpose: The purpose of the research is to find a method of identifying suspicious transactions in datasets, where the risk factor is related to the overvaluation of goods covered under export procedure and data that are affected by areas of extra high density.

Research methodology: The proposed methodology is two-step. Firstly, to eliminate areas of extra high density, with the use of a sampling scheme set reciprocally to the intensity point pattern, defined by means of a two-dimensional kernel estimator. Next, based on sampled data, a quantile regression model is built. Moreover, the inference about the type of model is provided by using the Khmaladze test.

Results: The example highlights the benefits of the use of the two-step approach in model building. The proposed methodology provides the foundation for the inference by means of the Khmaladze test. The reliable threshold for selecting the suspicious transactions can be built.

Novelty: The paper addresses some of the previously identified issues in a two-dimensional intensity assessment. Moreover, the proposed methodology based on quantile regression and the Khmaladze test provides the foundation for the customs gap measure in export data.
\end{abstract}

Keywords: kernel density, the Khmaladze test, quantile regression, customs gap, clearance, export, trade in goods

JEL classification: C21, C52, C55, F47 


\section{Introduction}

The main revenue of the European Union is based on three components: Customs duties and levies, Value Added Tax, and Gross National Income (GNI) based resources. In the years 2014-2018, the relative share of EU resources was changed by almost 5\% from year to year. ${ }^{1}$ The unpredictability in VAT or custom duties in the case of frauds could be a disproportionate cost burden in relation to the size of the GNI's of MS countries. This kind of situation can have a destructive impact on the EU economy. Actions performed by the EU Commission, as well as all of the member states, should be focused on providing a proper and stable mechanism of the audit and collection of customs and tax duties. Based on the latest study of the Policy Department for Budgetary Affairs (Van der Paal et al., 2019), in the European Union the estimated impact of customs and customs-related VAT frauds is not known. The authors highlight the fact that the EU Parliament, together with the Court of Auditors, requested the European Commission to provide the proper statistics and estimates of the assessment of the customs gap. In their opinion, the situation is implicated by several conditions and one of them is the lack of holistic methodology, which could provide the expected estimates. The authors of the mentioned study highlight the issue where the identified cases of customs and customs related VAT frauds can exemplify the scale of the problem. ${ }^{2}$

On top of this, there are regulations and responsible bodies forming the risk management system. The customs risk management framework ${ }^{3}$ applied in the EU (compare to (Oroszki, 2019), (EC Europa, 2019c) is the foundation of a process of trade in goods where not only the customs service and the revenue administration authorities, but also other bodies are involved in this multilevel process. ${ }^{4}$ The full-cycle of anti-fraud activities on different levels of processing are as follows: prevention, detection, investigation and response. ${ }^{5}$

The study of customs data in the context of an antifraud analysis can be performed in many different ways. The scope and quantitative methods can differ. Most of them are focused on the following methods: heuristic algorithms (Riani, Atkinson, Cerioli, 2012), regression and clustering problems (Cerioli, Perrotta, 2014) or methods based on the Newcomb-Benford law

\footnotetext{
1 See appendix A, based on the EC Europa (2019a).

2 The details can be found in the following documents: EU Parliament report (Special Report No. 01/2019: Fighting Fraud in EU Spending: Action Needed, n.d.), EU parliament resolutions (European Parliament, 2018) exemplify the issues with the customs gap measurement and the cases of customs and customs related VAT frauds.

3 This definition of the risk management system is general and covers customs, as well as, customs related VAT fraud.

${ }^{4}$ In the EU the main bodies engaged in anti-fraud activities are as follows: OLAF, IDOC, Commissions DGs, Eurojust, Europol, NAA, National judicial/law enforcement authority EPPO.

5 The full-cycle of anti-fraud practices and detailed list of bodies engaged in the process were covered in detail in Oroszki (2019).
} 
(Cerioli, Barabesi, Cerasa, Menegatti, Perrotta, 2019). This research focused mostly on the import procedure where the customs declaration was the main point of the interest.

The main concern of the article is customs and customs-based VAT frauds, which are strongly related to the trade in goods with third countries (Ruiz, 2019) under export procedures. The proposition of the study meets the expectations related to the practical aspect of the customs risk management framework, as well as, the technical requirements and restrictions of the operational systems responsible for providing a risk analysis service.

The focus is twofold:

- to build the statistically based methodology for identifying the potential outliers in a dataset, which can be suspected as illicit,

- to create a framework based on simple business rules, which can be implemented in the clearance environment or used as feeder models for a detailed ex-post analysis.

The rest of the article is organised as follows: The first section provides the background for the trade in goods with reference to the most important issues regarding the electronic dataprocessing, clearance system and customs risk controls process. In the second section, the author covers a description of the problem from the qualitative perspective, with reference to similar research. The economic relationship, being the foundation of the research, is defined. The methodology is presented with an example which covers the main aspects of the study. At the end, the conclusions are provided along with the recommendations for future research.

\section{Practical aspects of trade in goods between the EU and third countries}

A customs declaration is a legal act where the party declares its willingness to place goods under a given procedure (the details are covered under the articles, 5, and 158-187 of the Union Customs Code - UCC), (EC Europa, 2019b). The customs declaration is made by means of electronic data-processing ${ }^{6}$ while risk management is a process carried out by the customs services of EU member states. This process is carried out through specific IT systems providing a risk analysis service for the clearance system. Based on the information provided in the EU fact and figures report from 2016 (Thomas, 2018), 99\% of import and export declarations were submitted by means of electronic inputs. More than $93 \%$ were cleared under one hour, and $67 \%$ of them were cleared within 5 minutes. Regarding the export procedure, in 2017 more than 325

\footnotetext{
${ }^{6}$ The SAD, and other customs declarations are sent as XML documents into National Systems, hereinafter referred to as operational systems. Specific and rare cases of deviations from this process are set out in the UCC act.
} 
million items in approximately 144 million declarations were submitted in clearance systems (EC Europa, 2019d).

These numbers highlight the practical aspect of the challenges and limitations of effective customs controls. These controls can be applied directly in clearance systems while the customs declaration is processed and goods are moved, or ex-post after the respective declarations end and controls are made at the registered office of the entity.

\subsection{The scope of the customs controls}

The customs risk management framework is a multi-level process. Customs controls can be focused on many aspects, but one of the most common is, the time and the scope of such controls.

With respect to the time of performing control activities, they are as follows:

1. Ex post controls - the audit is performed after the customs procedure took place. This process is carried out beyond customs operational systems and is activated by the human factor, based on expert knowledge, statistical models or external information. ${ }^{7}$

2. Real-time controls - the audit is performed at the moment of the customs procedure. This kind of operation is processed in the customs operational system and is activated automatically by predefined triggers (customs risk profiles), applied inside the IT infrastructure.

Regarding the scope of the performed control and risk factors, the audit can be focused on the following:

- where the risk factor is the entity involved in the process, i.e. importer, exporter, carrier, or natural person involved in the customs procedure,

- where the risk factor is the goods placed under a given customs procedure, and all its characteristics, are as follows: value, quantity, condition of transportation, country of origin or destination, and many others.

The proposed methodology covers the expectation of the real-time controls as well as the ex-post inspection. The solution is mainly focused on the risk factor related to the traded goods. The main application of the proposed solution regards the clearance systems or ex-post controls in the following forms:

- as the risk profiles used directly in the operational systems, where all the information is included in the customs declaration,

\footnotetext{
7 External information can be provided by other customs services, other bodies engaged in anti-fraud activities or even denunciations.
} 
- as the feeder models ${ }^{8}$ to the more detailed analysis, where the risk factor is the entity involved in the process, or as the input to other statistical models or judgement-based frameworks.

\section{Definition of the problem from a quantitative perspective}

This research is focused on export procedure and VAT related fraud types. A similar direction of the research, regarding import procedure issues within one of the EU member states was raised previously in the research (Cerioli, Perrotta, 2014). In the cited paper the authors based the modelling on two steps. The identification of the areas of extra high density using the kernel estimator was the preliminary step. Secondly, classifications of the goods with the gaussian mixture model on the selected sample were performed. The sampling scheme was defined as reciprocal to the intensity defined in the first step. This treatment gave the opportunity to eliminate some of the modelling issues. In this research, the author takes the idea of the identification of areas of extra high density by means of intensity estimation using the kernel function. The purpose of the identification of the areas of extra high density in the presented research has a similar motivation, i.e. to eliminate some of the modelling restrictions. ${ }^{9}$ However, current research addresses some of the issues identified in previous studies. The second step of the proposed methodology is novel. It uses a different economic reasoning, as well as, a different statistical model, which is quantile regression. Moreover, the regression model is supported by the statistical test to assess the heteroscedasticity to fill any potential gaps in reasoning based only on the regression model. The solution is robust and gives straightforward reasoning for the next steps in customs controls.

The purpose of the analysis is to create a framework for identifying the goods in the export declaration, which can be treated as the unusual observation (the potential outlier affected by the illicit transaction), with reference to the population from where it is taken. The population is defined as the basis of the combined nomenclature codes, where the different codes defined the goods under the respective procedure. ${ }^{10}$ In the analysed case the most granular level of the

\footnotetext{
8 Feeder model-term describing the situation in which the results of one model create an input to another model.

9 The modelling restrictions are the same in the concept, i.e. areas of extra high density do not allow to properly using the estimation procedures in the next step, but the details of the second step are based on the quantile regression model rather than the classification.

${ }^{10} \mathrm{CN}$ codes, i.e. the Combined Nomenclature are tools for classifying goods. (EC Europa, 2019e). Currently, there are more than 9,000 CN8 codes, i.e., the 8 digits codes and more than 15,000 CN10 codes, where the additional 2 digits allow for a more detailed description of the goods. Under the import procedure, 10 digits are obligatory while the export procedure requires only 8 of them.
} 
analysis is CN8. The scale of the problem, in practice, covers several thousands of populations and the regular model building and analysis is impossible in a reasonable amount of time. Moreover, the expectation of the national administrative authorities and other bodies involved in anti-fraud activities or the EU Commission can be focused on robust, holistic and simple solutions which are possible to implement directly in the current IT environments to ensure basic security of one of the main revenues in the EU. The projected solution is also easy to use during the investigation when declared goods are highlighted as suspicious and directed to the formal control procedures by the customs officers.

\subsection{Economic relationship being modelled}

The foundation of the research is the economic relationship which involves two variables: the value of goods and quantity defined as the mass of item or the supplementary unit. ${ }^{11}$ The level of granularity on the CN8 level defines the individual range of the model building. ${ }^{12}$

\subsection{Identification of outliers in individual cases}

The definition of intensity of the process should be preceded by the definition of the point pattern. The point pattern analysis is focused on the research where the object of the study is the area, locations of items inside this area, as well as, their size or other characteristics. The common issues are referred to the clustering of the data points in the space. The general definition of the point process is based on the 'stochastic mechanism, which generates a countable set of events' (Diggle, 2003) after (Bivand, Pebesma, Gómez-Rubio, 2013, p. 173), the locations of which are defined as point patterns. Many additional covariates can be defined with relation to those point patterns. One of them is the volume (or the size). The main concern of the analysis of point patterns is the inference about the spatial distribution. Regarding the spatial distribution, two kinds of properties are defined (Baddeley, Rubak, Turner, 2015; Bivand et al., 2013). The first order properties define the density and intensity of the process, while the second order properties define interactions between the different point patterns. ${ }^{13}$ In this context the Poisson process can

\footnotetext{
11 The second variable defined as mass or supplementary units depends on the specific CN code. The customs tariff defines in which cases the supplementary unit is obligatory.

12 The results of the analysis were previously presented as a speech at the conference ECDA2017, where the author was invited by the IPSC-JRC Ispra (Joint Research Center - Institute for the Protection and Security of the Citizen in Ispra). The data used in the analysis contained only standardised information about a volume, and quantity with the information about the $\mathrm{CN} 8$ level, of the goods under export procedure in one of the member state countries. The presented exemplification regards the one selected $\mathrm{CN} 8$, covering the one type of goods under the export procedure. Currently, the presented problem, as well as, the results are novel and were not previously included, partly or entirely, in any kind of research or technical papers or submitted to any publisher.

13 Interactions allow to model clusters between the point patterns.
} 
be used. ${ }^{14}$ Moreover, the intensity can be homogeneous or non-homogeneous. The homogenous Poisson process refers to the situation where all events are independently and uniformly distributed in the analysed areas. However, from the perspective of the study, the main interest regards the non-homogeneous cases, where the non-constant intensity is modelled. One of the possibilities is to use the non-parametrical methods, for example, the kernel smoothing. The kernel estimator can be defined as the function of (Bivand et al., 2013, p. 184): ${ }^{15}$

$$
\hat{\lambda}(x)=\frac{\frac{1}{h^{2}} \sum_{i=1}^{n} \kappa\left(\frac{x-x_{i}}{h}\right)}{q(x)}
$$

where the $\kappa(u)$ is the bivariate symmetrical kernel function, the $q(x)$ is the edge correction factor, and $h$ is the bandwidth value controlling the degree of smoothing. In the study, the isotropic gaussian kernel was used. The other parameters responsible for the kernel definition will be shown in the following examples.

\subsection{The exemplification of the problem in two-dimensional space}

The example presented in Figure 1 reflects the issues with extra high density, which are as follows:

1. Areas of contamination of the data.

2. Presence of heteroscedasticity.

3. Potential linear relationships in the selected regression quantiles.

The analysed declarations under the export procedure can be endangered by the VAT related fraud in the upper part of the figure. Only overvaluation gives the opportunity for profits above the average (above the economical expectation, when the market mechanism works properly, this is due to the fact of possible fraud). The outliers under the main trend of data are of less concern in the presented case (this kind of issue can be a main point of interest when analysing the import procedure ${ }^{16}$ ). Moreover, in the analysed examples, the population can be a composition of many subpopulations, but the analysis of the potential use of other covariates is beyond the scope of the current research. This kind of hypothesis can be analysed in selected

\footnotetext{
14 Another possibility is to use parametrical methods, as the MLE, but in the analysed cases it could be hard to define one parametric solution, which provides reliable estimates in unpredictable cases, i.e., for all the domains of relationships for all goods covered under the CN8 codes.

15 All the calculations presented in the research were derived from the R environment. The intensity assessment was based on the spatstat library, and the quantile regression assessment and further inference was based on the quantreg library.

16 The undervaluation is one of the main risks related to the import of goods.
} 
cases after the suspicious transaction is expanded to the second line of controls during the online or ex-post examination. The remaining issue related to this kind of data is the contamination of point patterns close to each other or even one another. The analysis of the flat data in Figure 1 makes the impression of a single point pattern. Some of the points may be compositions of observations with the exact or almost exact values. This kind of issue can start a problem at the parameter estimation step. The areas of extra high densities, potentially hidden on plots (without the information about the density dimension), can hold the estimation close to groups of points implicating the output of unpredictable and unacceptable results. The elimination of these cases gives the opportunity to bypass future problems regarding the estimation of model parameters or the procedures of hypothesis testing. ${ }^{17}$

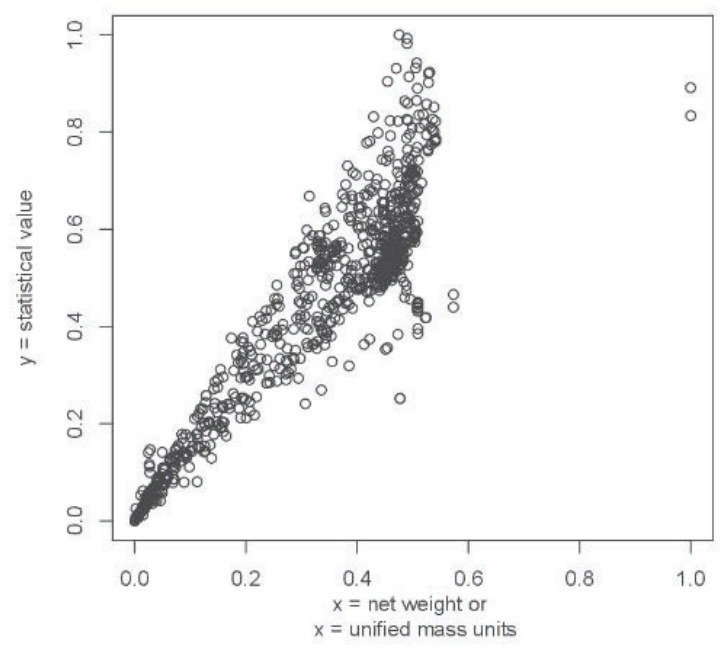

Figure 1. The relationship between the value and quantity in one selected $\mathrm{CN} 8$ code $^{18}$ Source: own elaboration.

The following figures show the process of adding subsequent arguments to the kernel density estimator. Adding more restrictions reflects the underlying problem in a better way.

\footnotetext{
${ }^{17}$ In the referenced paper (Cerioli, Perrotta, 2014) the authors provide small changes to the dataset, where the exact contamination issues exist. The present research addresses this issue with the use of information weighting, as in Figure 2D.

18 i.e. one type of goods.
} 
A. Solution without any attributes

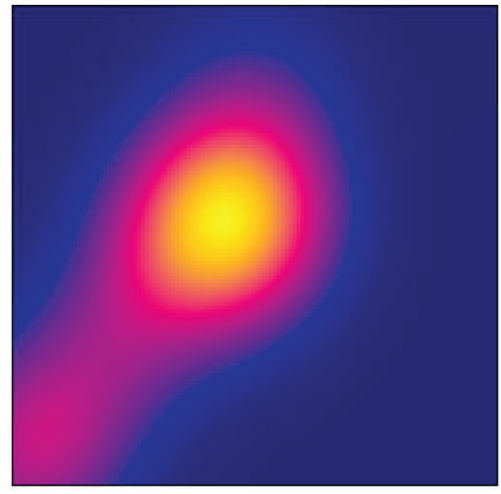

C. Scott bandwidth added

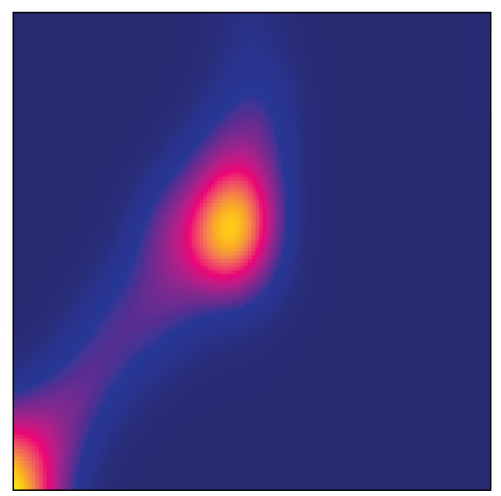

B. Edge correction added
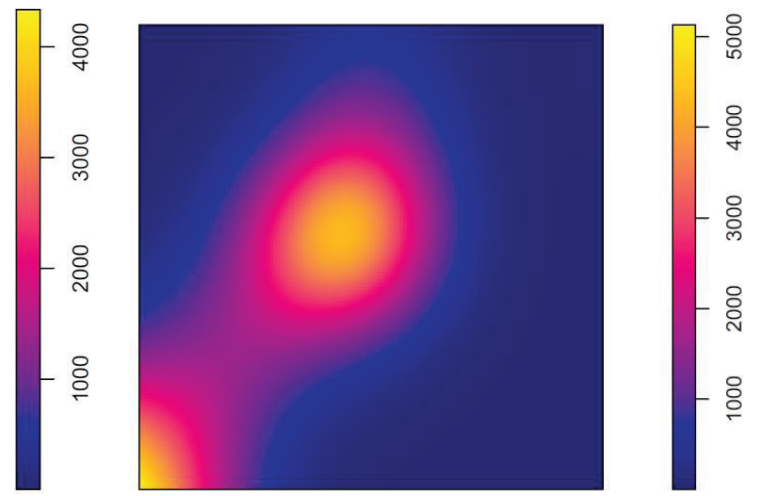

D. Diggle's correction and volume weight added

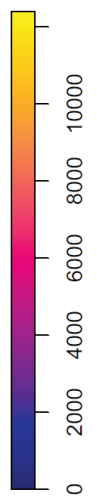

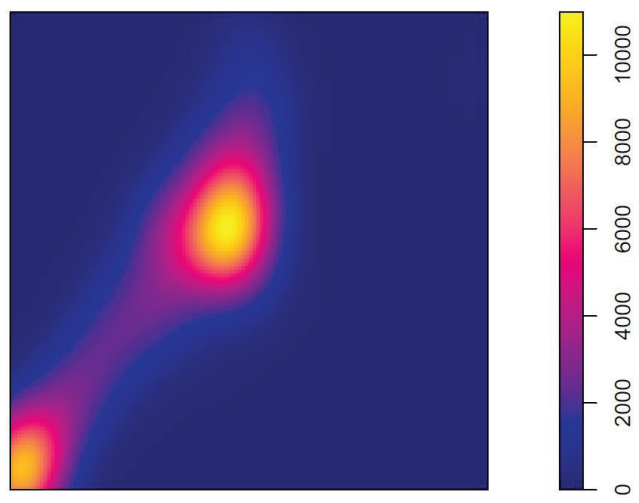

Figure 2. Two-dimension kernel smoothing with additional parameters added in each step Source: own elaboration.

In Figure 2, the process of two-dimension kernel smoothing is presented. In each step a new set of parameters was added. The figure presents the progressive process of smoothing adjustments to the data. Those steps added specific features to the kernel function. They were as follows:

1. In Figure $2 \mathrm{~A}$ there is a lack of any additional parameters.

2. The example (B) adds the edge correction- which gives the ability to correctly access the point pattern close to the edges of the subregion. High density close to origin was previously omitted by the kernel smoothing and after edge correction restriction, this area is more emphasized. 
3. Bandwidth correction in plot (C), with a heuristic algorithm, gives more insight into the underlying data process. There are other algorithms based on the cross validations or MLE procedures, however, but in this study, the simple Scott rule for bandwidth was selected.

4. Additional parameters added in step (D) were the Diggle correction and volume weight correction. The former gives the opportunity to improve edge correction, and the latter gives an opportunity to provide information about the multiple point contamination with use directly in the estimation process. ${ }^{19}$

\subsection{Sampling reciprocal to the intensity}

The main goal of the previous paragraph was to identify the areas of unusual contamination and create the basis for the sampling reciprocal to the intensity pattern. The sampling scheme was set as the increasing log function with the manually selected parameters where the number of sampled points in the case of the biggest datasets would result in not more than a few thousand pieces of data provided for the next step..$^{20}$ The sampling reciprocal to the intensity was defined by means of the proportional relation: $:^{21}$

$$
p\left(v_{i}\right) \propto 1-\tilde{\lambda}\left(v_{i}\right)
$$

where the $\tilde{\lambda}\left(v_{i}\right)$ is the estimated intensity related to the point pattern $v_{i}$. Value of $\tilde{\lambda}$ is standardized on the $[0,1]$ interval.

Assuming the data from the Figure 1 are sampled with the reference to the relation given by (2) and intensity estimated as in Figure 2D, one exemplification of sampling is presented below:

\footnotetext{
19 The previously mentioned solution was based on the small changes provided into the dataset. In relation to the method used this kind of operation is unnecessary. It is better to provide the proper information about all features during the estimation process.

${ }^{20}$ When the dataset contains a huge number of observations it can be misleading to take a predetermined sample size proportional to the base dataset. In such cases the contaminations structures in such cases can remain in the data.

21 This kind of straightforward solution were presented in the mentioned position (Cerioli, Perrotta, 2014), in the current research the author adopts this as well.
} 
A. All data on the intensity surface

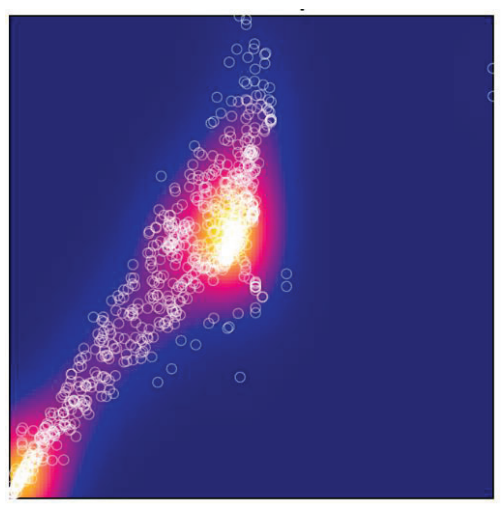

B. Sampled data on the intensity surface

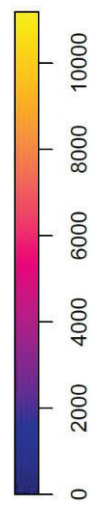

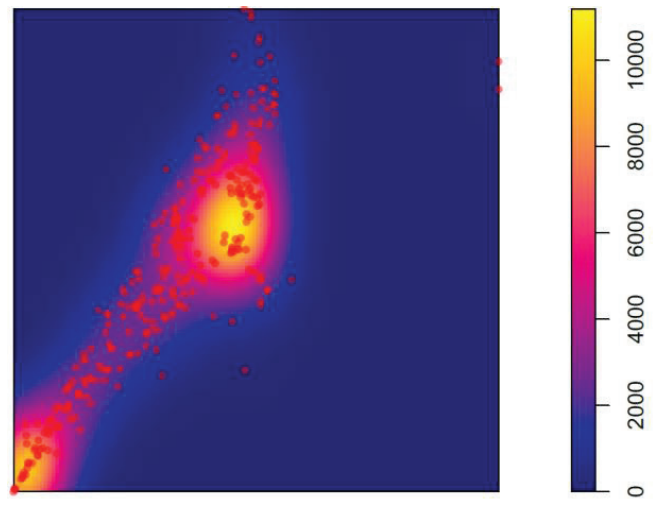

Figure 3. Sampling with reference to intensity

Source: own elaboration.

\subsection{Quantile regression line as a conditional threshold}

The main goal of applying the quantile regression model is to set the conditional threshold rule, where only the values lying above the line are of main interest. The selection of the quantile regression model is motivated by two major things:

1. Quantile regression gives a more complete picture of the problem, especially, when the main interest of the analysed patterns is related to the conditional quantiles.

2. Quantile regression is beneficial when the data can be affected by the heteroscedasticity. Moreover, the location shift effect or the location-scale shift effect of the covariates on the response can be analysed.

\section{Definition of the quantile regression model}

The quantile regression model is defined as follows:

$$
F_{y_{i} \mid x_{i}}^{-1}\left(\tau \mid x_{i}\right)=x_{i}^{\tau} \beta(\tau)
$$

where the $\tau \in \mathrm{T}$ and the $\mathrm{T} \subset[0 ; 1]$, and the linear model can be defined:

$$
y_{i}=x_{i}^{T} \alpha+\left(x_{i}^{T} \gamma\right) u_{i}
$$


where the specific cases can be defined as:

- Heteroscedasticity, where $x_{i}^{T} \gamma=\gamma_{0}+z_{i}^{T} \gamma_{1}$

$$
F_{y_{i} \mid x_{i}}^{-1}\left(\tau \mid x_{i}\right)=x_{i}^{T} \alpha+\left(x_{i}^{T} \gamma\right) F_{0}^{-1}(\tau)
$$

- Homoscedasticity, where $\gamma_{1}=0 ; x_{i}^{T} \gamma=\gamma_{0}$

$$
F_{y_{i} \mid x_{i}}^{-1}\left(\tau \mid x_{i}\right)=x_{i}^{T} \alpha+\gamma_{0} F_{0}^{-1}(\tau)
$$

A separate definition for the hetero and homoscedasticity is the foundation for the location shift effect (LS) or the location-scale shift (LSS) effect assessment. The modified version of the Kolmogorov-Smirnov statistic, used for the identification of the specific case, is as follows (Khmaladze, 2013; Khmaladze, Koul, 2004, 2009):

$$
K_{n}=\sup _{\tau \in\left[\tau_{0}, \tau_{1}\right]} \tilde{v}(\tau)-\tilde{v}\left(\tau_{0}\right) / \sqrt{\tau_{1}-\tau_{0}}
$$

For the LS or LSS effects assessment the H0 hypothesis are defined as:

- LSS problem: $\mathrm{H}_{0}: \beta(\tau)=\alpha+\gamma F^{-1}(\tau)$.

- LS problem: $\mathrm{H}_{0}: \beta(\tau)=\gamma_{0}$.

In Figure 4A, the quantile regression model is applied for all data without any changes and, on the sampled data, where the sampling scheme is reciprocal to the point intensity pattern. Several $\tau$ parameters for the quantile regression model are chosen. ${ }^{22}$ The data without the proposed sampling scheme hold the estimation procedure around the contamination area. Figure $4 \mathrm{~B}$ reflects the effect of applying the sampling scheme where the quantile regression lines are distributed more regularly. Moreover, the Khmaladze test (for the LS and LSS case) is applied for the models where the $\tau \geq 0.6$. For the models built on all data, hypothesis $\mathrm{H}_{0}$ is rejected for all the LS and the LSS cases. For the models built on the sampled data, in most of the cases the LSS hypothesis was not rejected, identifying the heteroscedastic pattern correctly. The identification of the LS or the LSS pattern is necessary to ensure credibility of the threshold and stability of the solution. The model with the highest $\tau$ parameter (assuming the hypothesis for the LS or LSS case will not be rejected) should be used as a threshold. Further conditions can be applied only for the data above the chosen regression line.

${ }^{22}$ The $\tau \in[0.2 ; 0.8]$ with step $2.5 \%$. 
A. Quantile regression on all data

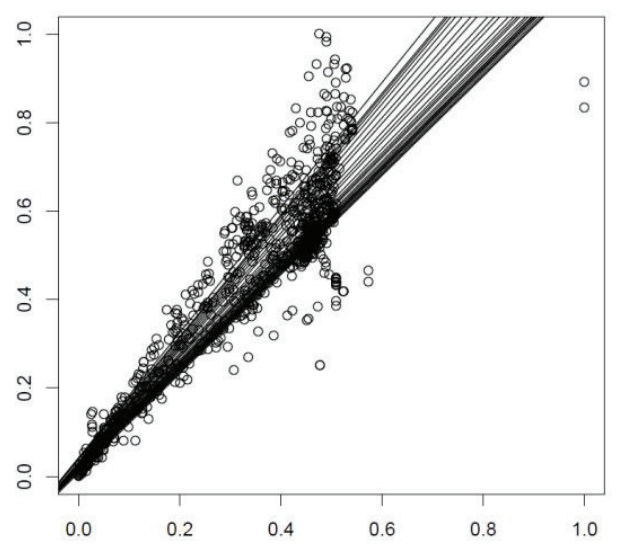

B. Quantile regression on sampled data

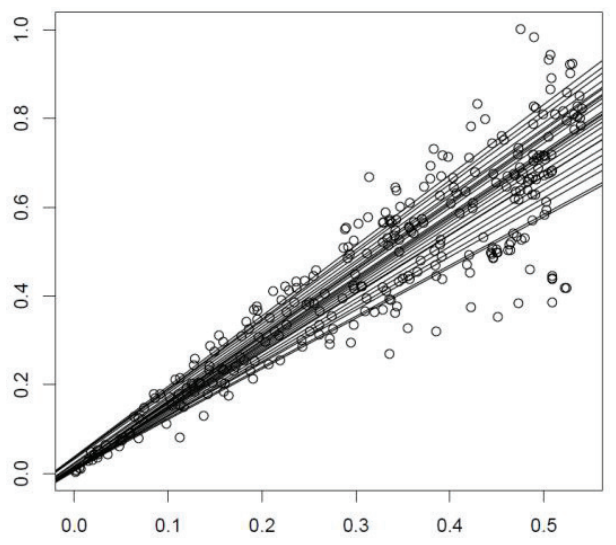

Figure 4. Sampling with reference to intensity on two datasets

Source: own elaboration.

The summarised output of the Khmaladze test for the $\tau=0.8$ is provided in appendix B. The expected output from the model development process is the location scale shift model. This assumption is confirmed with use of the Khmaladze test only on the sampled data, without the contamination of data at the origin and in the middle of the domain. Without sampling reciprocal to the intensity, the proper inference based on the Khmaladze test would not be possible in the analysed case.

\section{Conclusions}

The motivation for the research was twofold. To create the methodology potentially applicable to the current clearance systems, or ex-post controls, as well as, to provide the solution which could be the base for the assessment of the potential customs gap in the export procedure. The issues identified during the study address previous limitations identified in other research. From the perspective of customs service, the most valuable information is that obtained during the movement of goods. All ex-post controls are necessary, but they are burdened with the lack of the main subject of analysis, i.e., the commodity. Only the controls taken directly on the clearance system and during the customs procedures give the possibility to hold the commodity at the border or in transit, and provide cross checks between the goods and the information from the related documents as well as, with other systems, and also internally among the customs service of the member state. The proposed solution provides a clear, simple, 
and economic-reasoning based solution, which could be implemented without much effort by means of business rules in a clearance system. However, the methodology will not provide the answers in all the analysed dimensions, ${ }^{23}$ and in selected cases an additional analysis can be beneficial. Especially, in the case when the H0 hypothesis for the Khmaladze test is rejected the first starting point should consider the occurrence of subpopulations in the data, which can be one of the future directions of the research. In this context, it is beneficial to consider the work of Cerioli and Perrota (2014) in the analysis of subpopulation in customs data. Moreover, some points of interest arise from the recent works on the Newcomb-Benford Law, where the heuristic based reasoning is supported by the formal statistical test (Cerioli et al., 2019).

Many complementary solutions, including the presented method, can provide a potential control of the rate of false rejections at each stage of the customs procedure and they can strengthen the clearance system. Nevertheless, business or expert domain knowledge may be required in more complicated cases, when the commodity is related to a high-level manufacturing process or when it is made with the use of high technologies.

\section{Appendix A}

The distribution of the own resources of the EU in the years 2014-2018. Based on the statistics 2000-2018 (EC Europa, 2019a)

\begin{tabular}{|l|c|c|c|c|c|}
\hline Years & 2018 & 2017 & 2016 & 2015 & 2014 \\
\hline VAT-based own resource & $11.8 \%$ & $14.0 \%$ & $11.6 \%$ & $14.8 \%$ & $12.7 \%$ \\
\hline GNI-based own resource & $71.1 \%$ & $65.0 \%$ & $70.0 \%$ & $64.4 \%$ & $71.4 \%$ \\
\hline Customs duties $(100 \%)$ & $17.1 \%$ & $21.0 \%$ & $18.3 \%$ & $20.8 \%$ & $15.9 \%$ \\
\hline Nominal value & 148,801 & 120,974 & 136,459 & 122,114 & 138,741 \\
\hline
\end{tabular}

\section{Appendix B}

Output from the Khmaladze test performed in the R environment and with the use of the library (quantreg). Two kinds of Khmaladze tests are performed, i.e., for the location-shift and location-scale-shift and for two datasets. The first case covers the Khmaladze test for LS and LSS for all data. The second case covers the Khmaladze test for LS and LSS for sampled data. Only for the last case, i.e., for the LSS case on the sampled data, the test does not reject the $\mathrm{H} 0$ hypothesis about the assumed relationship. The data are identified as the location scale shift model, i.e., as the linear model with heteroscedasticity.

\footnotetext{
${ }^{23}$ The dimensions are defined in means of the combined nomenclature i.e. in the case of exports it should be the CN8 level.
} 


\section{All data}

Khmaladze test for all data.

Khmaladze test for the location-shift

Joint test is significant at a $5 \%$ level

Test(s) for individual slopes:

significant at the $5 \%$ level

Value $=2.322373$

$\operatorname{Pr}=0.05$

Khmaladze test for the location-scale-shift hypothesis

Joint test is significant at the $1 \%$ level

Test(s) for individual slopes:

significant at the $1 \%$ level

Value $=3.531779$

$\operatorname{Pr}=0.01$

Sampled data

Khmaladze test for the location-shift hypothesis

Joint test is significant at the $5 \%$ level

Test(s) for individual slopes:

significant at the $5 \%$ level

Value $=2.562373$

$\operatorname{Pr}=0.05$

Khmaladze test for the location-scale-shift hypothesis

Joint test is not significant at the $10 \%$ level

Test(s) for individual slopes:

not significant at the $10 \%$ level

Value $=1.434805$

$\operatorname{Pr}=1.0$

\section{References}

Baddeley, A., Rubak, E., Turner, R. (2015). Spatial Point Patterns: Methodology and Applications with $R$. CRC Press.

Bivand, R.S., Pebesma, E., Gómez-Rubio, V. (2013). Applied Spatial Data Analysis with R. Springer New York. Retrieved from: http://link.springer.com/10.1007/978-1-4614-7618-4 
Cerioli, A., Barabesi, L., Cerasa, A., Menegatti, M., Perrotta, D. (2019). Newcomb-Benford law and the detection of frauds in international trade. Proceedings of the National Academy of Sciences, 116 (1), 106-115. DOI: 10.1073/pnas.1806617115.

Cerioli, A., Perrotta, D. (2014). Robust clustering around regression lines with high density regions. Advances in Data Analysis and Classification, 8 (1), 5-26. DOI: 10.1007/s11634013-0151-5.

Diggle, P.J. (2003). Statistical Analysis of Spatial Point Patterns (2 edition). Hodder Education Publishers.

EC Europa (2019a). EU expenditure and revenue 2014-2020 [Text]. European Commission - European Commission. Retrieved from: https://ec.europa.eu/info/about-european-commission/eu-budget/documents-and-figures/documents-test_en.

EC Europa (2019b, August 1). Customs declaration [Text]. Taxation and Customs Union European Commission. Retrieved from: https:/ec.europa.eu/taxation_customs/business/ customs-procedures/general-overview/customs-declaration_en.

EC Europa (2019c, August 1). Customs Risk Management Framework (CRMF) [Text]. Taxation and Customs Union - European Commission. Retrieved from: https://ec.europa.eu/ taxation_customs/general-information-customs/customs-risk-management/measures-customs-risk-management-framework-crmf_en.

EC Europa (2019d, August 1). EU Customs Union - unique in the world [Text]. Taxation and Customs Union - European Commission. Retrieved from: https://ec.europa.eu/taxation customs/facts-figures/eu-customs-union-unique-world_en.

EC Europa (2019e, August 1). The Combined Nomenclature [Text]. Taxation and Customs Union - European Commission. Retrieved from: https://ec.europa.eu/taxation_customs/ business/calculation-customs-duties/what-is-common-customs-tariff/combined-nomenclature_en.

European Parliament (2018, 10). European Parliament resolution - Fighting customs fraud and protecting EU own resources. Retrieved from: http://www.europarl.europa.eu/doceo/ document/TA-8-2018-0384_EN.html.

Khmaladze, E. (2013). Note on distribution free testing for discrete distributions. The Annals of Statistics, 41 (6), 2979-2993. DOI: 10.1214/13-AOS1176.

Khmaladze, E.V., Koul, H.L. (2004). Martingale transforms goodness-of-fit tests in regression models. The Annals of Statistics, 32 (3), 995-1034. DOI: 10.1214/009053604000000274.

Khmaladze, E.V., Koul, H.L. (2009). Goodness-of-fit problem for errors in nonparametric regression: Distribution free approach. The Annals of Statistics, 37 (6A), 3165-3185. DOI: 10.1214/08-AOS680.

Oroszki, J. (2019). Fraud risk for the EU budget - what the ECA recommends. ECA Journal. Fraud and Corruption, 2, 26-33. 
Riani, M., Atkinson, A., Cerioli, A. (2012). Problems and Challenges in the Analysis of Complex Data: Static and Dynamic Approaches. In: Advanced Statistical Methods for the Analysis of Large Data-Sets (pp. 145-157). Springer, Berlin, Heidelberg. Retrieved from: https://link.springer.com/chapter/10.1007/978-3-642-21037-2_14.

Ruiz, C.S. (2019). How criminals evade VAT and how we use new techniques to detect it. $E C A$ Journal. Fraud and Corruption, 2, 37-44.

Special report No. 01/2019: Fighting fraud in EU spending: Action needed (n.d.). Retrieved from: https://www.eca.europa.eu/en/Pages/DocItem.aspx?did=48858 (26.10.2019).

Thomas, I. (2018, 01). Parliamentary questions- Fighting customs fraud and protecting EU own resources. Retrieved from: http://www.europarl.europa.eu/doceo/ document/O-8-2018-000007_EN.html.

Van der Paal, J., Nurk, A., De Vlieger, D., Janne, H., De Ramon, M., Heeren, P. (2019). Protection of EU financial interest on customs and VAT: Cooperation of national tax and customs authorities to prevent fraud (PE 636.470; Policy Department D for Budgetary Affairs, p. 112). 